\title{
Serum Levels of Pro- and Anti-Inflammatory Cytokines in Threatened Miscarriage in Pregnant Women within Owerri Metropolis, Nigeria
}

\author{
Maduka Ignatius $\mathrm{C}^{\mathbf{1}}$ and Uzoho Cynthia $\mathrm{T}^{2 *}$ \\ ${ }^{1}$ Department of Human Biochemistry, Nnamdi Azikiwe University, Nigeria \\ ${ }^{2}$ Department of Medical Laboratory Science, Nnamdi Azikiwe University, Nigeria \\ *Corresponding author: Uzoho CT, Department of Medical Laboratory Science, Nnamdi Azikiwe University, Nnewi \\ campus, Nigeria
}

\section{ARTICLE INFO}

Received: 慧 March 11, 2020

Published: 㓞 March 19, 2020

Citation: Maduka Ignatius C, Uzoho Cynthia T. Serum Levels of Pro- and Anti-Inflammatory Cytokines in Threatened Miscarriage in Pregnant Women within Owerri Metropolis, Nigeria. Biomed J Sci \& Tech Res 26(4)2020. BJSTR. MS.ID.004394.

Keywords: Pregnancy; Threatened Miscarriage; Pro-inflammatory; Anti-inflammatory Cytokines
Abstract

Pregnancy is a biological process whereby complex cytokine network play an important role. The phenomenon of pregnancy can be compromised by a number of complications, such as threatened miscarriage which could be as a result of cellular immune effectors. This study assessed the serum levels of pro (TNF-alpha and IL-2) and anti-inflammatory (IL-4 and IL-10) cytokines in threatened miscarriage in pregnant women within Owerri metropolis. A total of 140 women were recruited for this study; 60 pregnant women with threat of miscarriage and 40 apparently healthy pregnant women with no history of miscarriage, as well as 40 apparently healthy non pregnant women, who served as controls. Serum levels of Tumor Necrosis Factor (TNF) alpha, Interleukin-2 (IL-2), Interleukin-4 (IL-4) and Interleukin-10 (IL-10) were determined using Enzyme Linked Immunosorbent Assay techniques. Data were expressed as median and analyzed using Mann-Whitney test and Kruskal Wallis test, while anthropometric data were obtained using standard methods. P values $\leq 0.05$ were considered significant. Reproductive, medical information as well as information on lifestyle of the subjects were gathered with the aid of a questionnaire.

Demographic studies showed that among the pregnant women, who attend antenatal clinics, $79 \%$ are primi-varida while $21 \%$ are multi-varida. Also, among all the women included in this study, $18.6 \%$ were of the higher social class, $51.4 \%$ were of the middle class and $30 \%$ were of the lower class. There were no significant differences observed in the anthropometric variables of the three groups $(p>0.05)$. The results showed a significant increase in the median values of the pro-inflammatory cytokines of the pregnant women with threats of miscarriage, when compared with the apparently healthy pregnant women and non-pregnant women $(\mathrm{p}<0.05)$. Similarly, there were significant increase in the median values of the anti-inflammatory cytokines of the pregnant women with threats of miscarriage, when compared with the apparently healthy pregnant women and the non-pregnant women $(\mathrm{p}<0.05)$. There was no significant difference observed in TNF-alpha, IL-2 and IL-10 between the apparently healthy pregnant women and non-pregnant women $(p>0.05)$. However, there is a significant increase in IL-4 $(p<0.05)$ of the non-pregnant women compared to the apparently healthy pregnant women. Conclusively, the results showed severe increase in pro-inflammatory cytokines as well as moderate increase in the anti-inflammatory cytokines in the pregnant women with threats of miscarriage than the apparently healthy pregnant women and non-pregnant women. This could be used as biomarkers of threatened miscarriage. However, "personal cytokine profile" is advised especially in miscarriages where no clear etiologies have been identified. 


\section{Short Communication}

Pregnancy, also known as gestation, is the time during which one or more offspring develops inside a woman (Shehan, 2016). A multiple pregnancy involves more than one offspring, such as with twins [1]. Pregnancy can occur by sexual intercourse or assisted reproductive technology (Shehan, 2016). Childbirth typically occurs around 40 weeks from the last menstrual period (LMP). This is just over nine lunar months, where each month is about 291/2 days [2]. When measured from conception it is about 38 weeks. Symptoms of early pregnancy may include missed periods, tender breasts, nausea and vomiting, hunger, and frequent urination [3]. Pregnancy may be confirmed with a pregnancy test. Pregnancy is typically divided into three trimesters. The first trimester is from week one through 12 and includes conception. The first trimester carries the highest risk of miscarriage (natural death of embryo or foetus) [4]. The second trimester is from week 13 through 28 . The third trimester is from 29 weeks through 40 weeks. Miscarriage, also known as spontaneous abortion and pregnancy loss, is the natural death of an embryo or foetus before it is able to survive independently [4]. Threatened miscarriage-vaginal bleeding before 20 gestational weeks-is the commonest complication in pregnancy, occurring in about a fifth of cases. The most common symptom of a miscarriage is vaginal bleeding with or without pain, [4].

Tissue or clot-like material may also come out of the vagina. Among females who know they are pregnant, the miscarriage rate is roughly $10 \%$ to $20 \%$ while the rate among all fertilization is around $30 \%$ to $50 \%$ [4]. About $5 \%$ of females have two miscarriages in a row [5]. Several mechanisms involved in the pathogenesis of spontaneous abortion include chromosomal anomalies, hormonal problems, uterine abnormalities, infections, and autoimmune disorders [6]. Cytokine is a broad and loose category of small proteins that are important in cell signaling. Their release has an effect on the behaviour of cells around them. It can be said that cytokines are involved in autocrine signaling, paracrine signaling and endocrine signaling as immune-modulating agents. Their definite distinction from hormones is still part of ongoing research. Cytokines are produced by a broad range of cells, including immune cells like macrophages, B lymphocytes, T lymphocytes and mast cells, as well as endothelial cells, fibroblasts, and various stromal cells; a given cytokine may be produced by more than one type of cell [7]. They are important in health and disease, specifically in host responses to infection, immune responses, inflammation, trauma, sepsis, cancer, and reproduction. Cytokines are commonly classified in one or the other category: interleukin-1 (IL-1), tumour necrosis factor (TNF), gamma-interferon (IFN-gamma), IL-2, IL-12, IL-18 and granulocyte-macrophage colony stimulating factor (G-MCF) are well characterized as pro-inflammatory cytokines whereas IL4, IL-10, IL-13, IFN- $\alpha$ and transforming growth factor- $\beta$ are recognized as anti-inflammatory cytokines [8].
A pro-inflammatory cytokine or an inflammatory cytokine is a type of cytokine (signaling molecule) that is excreted from immune cells and certain other cell types that promote inflammation. Inflammatory cytokines are predominantly produced by helper $\mathrm{T}$ cells (Th) and macrophages and involved in the up regulation of inflammatory reactions (Zhang and An, 2007). The net effect of an inflammatory response is determined by the balance between pro-inflammatory and anti-inflammatory cytokines. Tumor necrosis factor, a pro-inflammatory cytokine, (TNF, tumor necrosis factor alpha, TNF $\alpha$, cachexin, or cachectin) is a cell signaling protein (cytokine) involved in systemic inflammation and is one of the cytokines that make up the acute phase reaction. It is produced chiefly by activated macrophages, although it can be produced by many other cell types such as CD4+ lymphocytes, natural killer (NK) cells, neutrophils, mast cells, eosinophils, and neurons [9]. Interleukin-2 (IL-2) is another pro-inflammatory cytokine. It is an interleukin, a type of cytokine signaling molecule in the immune system. It is a protein that regulates the activities of white blood cells (leukocytes, often lymphocytes) that are responsible for immunity. The interleukin 4 (IL-4) is a cytokine (anti-inflammatory) that induces differentiation of naive helper T cells (Th0 cells) to Th2 cells. Upon activation by IL-4, Th2 cells subsequently produce additional IL-4 in a positive feedback loop. The cell that initially produces IL-4, thus inducing Th0 differentiation, has not been identified, but studies suggest that basophils may be the effector cell [10].

Interleukin 10 (IL-10), also known as human cytokine synthesis inhibitory factor (CSIF), is an anti-inflammatory cytokine. In humans, interleukin 10 is encoded by the IL10 gene. IL-10 signals through a receptor complex, consisting of two IL-10 receptor-1 and two IL-10 receptor 2 proteins (Mosser and Zhang, 2008). Consequently, the functional receptor consists of four IL-10 receptor molecules. Although studies have been done on serum levels of proand anti-inflammatory cytokines in non-pregnant women, during pregnancy, labour and abortion (Vassiliadis et al., 1998), this study will be focused on serum levels of pro- and anti-inflammatory cytokines in threatened miscarriage in women during early pregnancy, apparently healthy pregnant women and non-pregnant women. This study therefore assesses the serum levels of pro (TNF-alpha and IL-2) and anti-inflammatory (IL-4 and IL-10) cytokines in threatened miscarriage in pregnant women within Owerri metropolis, Nigeria. The knowledge obtained will help to provide vital information needed by clinicians in the diagnosis and management of patients with threatened miscarriage in Owerri, Imo State, Nigeria.

\section{Materials and Methods}

\section{Study Area}

This study was carried out in selected hospitals and clinics in Owerri metropolis, Imo State, Nigeria. 


\section{Study Design/Subjects}

This is a case control study designed to assess the levels of TNF-alpha, IL-2, IL-4 and IL-10 cytokines in women with threat of miscarriage in Owerri metropolis, Nigeria. The subjects were made up of pregnant women aged between 18 and 35years, who were diagnosed of threatened miscarriage. Also, age-matched apparently healthy pregnant women with no sign or history of miscarriage and non-pregnant apparently healthy women were used as control subjects. A total number of 140 women were recruited for this study; 60 pregnant women with threat of miscarriage and 40 apparently healthy pregnant women with no history of miscarriage, as well as 40 apparently healthy non pregnant women, which served as controls. Questionnaires were used to obtain vital information on demographic data such as age, marital status, parity, gestational age, cigarette and alcohol consumption, prescribed drugs, medical history, occupation, and other activities at home. Ethical approval for this study was obtained from the Ethics Committee of Federal Medical Centre, Owerri, Imo state. Informed consent of participants was obtained before enrolment into the study. They were assured of confidentiality of the information obtained from them during and after the study.

\section{Biochemical Analysis}

Five millilitres (5mls) of blood were collected aseptically from all subjects by vein puncture technique from the cubital fossa into well labeled plain tubes. The samples were allowed to clot and then centrifuged at 4,000rpm for 10 minutes. The sera were then transferred into properly labeled plain tubes and stored at $-200 \mathrm{C}$. The cytokines were analyzed using ELISA method.

\section{Statistical Analysis}

The statistical analysis was done using SPSS V.22.0 program. Data were expressed as median. Comparisons were performed for anthropometric variables and analytical parameters using Kruskal Wallis and Mann-Whitney tests. Correlations were performed using Spearman's correlation. P value $\leq 0.05$ was considered significant.

\section{Result}

The results in Table 1 shows the median levels of some anthropometric variables in pregnant test group (A), pregnant control (B) and non-pregnant control subjects (C). The median values of the ages of the pregnant test group (A) 30.0years, pregnant control group (B) 29.5years and non-pregnant control group (C) 29.0years showed no significant difference $(p=0.844)$, likewise their ages when compared with one another; A vs B ( $p=0.698)$, A vs C ( $p=0.577)$ and $B$ vs $C(p=0.904)$. Similarly, there is no significant difference in height among the groups $(p=0.430)$ but with a significant increase when compared between group A and B ( $p=0.012$ ). Also, the median body weight of A $(65.0 \mathrm{~kg}), B(68.0 \mathrm{~kg})$ and C $(65.0 \mathrm{~kg})$ showed no significant difference $(p=0.095)$, except between groups B and C ( $p$ $=0.035$ ). There is no significant difference in the body mass index $(\mathrm{p}=0.211)$, systolic blood pressure $(\mathrm{p}=0.973)$ and diastolic blood pressure ( $\mathrm{p}=0.088)$ among the groups.

Table 1: Levels (median) of some anthropometric variables in pregnant test group, pregnant control and non-pregnant control subjects.

\begin{tabular}{|c|c|c|c|c|c|c|}
\hline Groups & Age (years) & Height (m) & Weight (kg) & BMI $\left(\mathrm{kg} / \mathrm{m}^{2}\right)$ & SBP (mmHg) & DBP (mmHg) \\
\hline $\begin{array}{l}\text { Pregnant test } \\
\text { (A) }\end{array}$ & 30 & 1.56 & 65 & 27.05 & 120 & 70 \\
\hline $\begin{array}{l}\text { Pregnant } \\
\text { control (B) }\end{array}$ & 29.5 & 1.6 & 68 & 26.95 & 120 & 70 \\
\hline $\begin{array}{l}\text { Non-pregnant } \\
\text { (C) }\end{array}$ & 29 & 1.58 & 65 & 26.67 & 120 & 70 \\
\hline $\begin{array}{l}\text { Kruskal Wallis } \\
\text { test }\end{array}$ & 0.34 & 6.303 & 4.712 & 3.115 & 0.056 & 4.863 \\
\hline $\mathrm{p}$-value & 0.844 & 0.43 & 0.095 & 0.211 & 0.973 & 0.088 \\
\hline A vs B & 0.698 & 0.012 & 0.136 & 0.313 & 0.861 & 0.279 \\
\hline A vs $C$ & 0.577 & 0.525 & 0.366 & 0.072 & 0.984 & 0.828 \\
\hline B vs C & 0.904 & 0.105 & 0.035 & 0.697 & 0.799 & 0.318 \\
\hline
\end{tabular}

Table 2 represents distribution of the subjects according to parity and social status. Some of the demographic data collected showed that among the pregnant subjects, $79 \%$ of them were primi-varida and $21 \%$ multi-varida. Among the pregnant test group, $80 \%$ were primi-varida and $20 \%$ were multi-varida. Similarly, $77.5 \%$ of the pregnant control group was primi-varida and $21 \%$ were multi-varida. The subjects were grouped according to social status and $18.6 \%$ were of the higher class, $51.4 \%$ were of the mid- dle class and $30 \%$ were of the lower class. Fifteen percent $15 \%$ ) of the pregnant test group were of the higher class, $51.7 \%$ were of the middle class and $33.3 \%$ were of the lower class. Among the pregnant control group, $17.5 \%$ were of the higher class, $57.5 \%$ were of the middle class and $25 \%$ were of the lower class. Also $25 \%$ of the non-pregnant control group was of the higher class, $45 \%$ middle class and $30 \%$ lower class. 
Table 2: Distribution of the subjects according to parity and social status.

\begin{tabular}{|c|c|c|c|c|c|}
\hline \multirow{2}{*}{ Group } & \multicolumn{2}{|c|}{ Parity $(\mathrm{N}=100)$} & \multicolumn{3}{|c|}{ Social status } \\
\hline & Primi-varida & Multi-varida & High & Middle & Low \\
\hline Pregnant test (A) & $48(80 \%)$ & $12(20 \%)$ & $9(15 \%)$ & $31(51.7 \%)$ & $20(33.3 \%)$ \\
\hline \multicolumn{6}{|c|}{$N=60$} \\
\hline $\begin{array}{l}\text { Pregnant con- } \\
\text { trol(B) }\end{array}$ & $31(77.5 \%)$ & $9(22.5 \%)$ & $7(17.5 \%)$ & $23(57.5 \%)$ & $10(25 \%)$ \\
\hline \multicolumn{6}{|c|}{$\mathrm{N}=40$} \\
\hline Non-pregnant (C) & - & - & $10(25 \%)$ & $18(45 \%)$ & $12(30 \%)$ \\
\hline \multicolumn{6}{|c|}{$\mathrm{N}=40$} \\
\hline Total $(\mathrm{N}=140)$ & $79 \%$ & $21 \%$ & $26(18.6 \%)$ & 72(51.4\%) & $42(30 \%)$ \\
\hline
\end{tabular}

Table 3 shows the median levels of TNF-alpha, IL-2, IL-4 and IL10 in pregnant test group (A), pregnant control (B), and non-pregnant control subjects(C). Using Kruskal Wallis test to compare the cytokines (TNF-alpha, IL-2, IL-4 and IL-10) analyzed among the subjects, there are statistically significant increase in TNF-alpha $(p<0.001)$, IL-2 $(p<0.001)$, IL-4 $(p=0.020)$ and IL-10 $(p<0.001)$ in pregnant test group $(\mathrm{A})$ when compared with the pregnant control group (B) and non-pregnant control group (C). Similarly, comparing between the groups using Mann Whitney test, there is a significant increase observed in TNF-alpha of A vs B $(p<0.001)$ and A vs $C(p<0.001)$ but no significant difference in B vs $C(p=0.923)$. Also, there exists a significant increase in IL-2 of A vs $B(p<0.001)$ and $A$ vs $C(p<0.001)$ but no significant difference in $B$ vs $C(p=0.606)$.

Table 3: Levels (median) of TNF-alpha, IL-2, IL-4 and IL-10 in pregnant test group, pregnant control, and non-pregnant control subjects.

\begin{tabular}{|c|c|c|c|c|}
\hline Groups & TNF-alpha (pg/mL) & IL-2 (pg/mL) & IL-4 (pg/mL) & IL-10 (pg/mL) \\
\hline Pregnant test subjects (A) & 12.4 & 19 & 0.85 & 0.7 \\
\hline Pregnant control (B) & 1 & 0.85 & 1.1 & 0.8 \\
\hline Non-pregnant control (C) & 0.7 & 0.75 & 7.837 & 30.7 \\
\hline Kruskal Wallis test & 57.829 & 57.829 & 0.02 & $<0.001$ \\
\hline p-value & $<0.001$ & $<0.001$ & 0.364 & 0.001 \\
\hline A vs B & $<0.001$ & $<0.001$ & 0.021 & $<0.001$ \\
\hline A vs C & $<0.001$ & $<0.001$ & 0.014 & 0.157 \\
\hline B vs C & 0.923 & 0.606 & & \\
\hline
\end{tabular}

For IL-4, there is a significant decrease noticed in A vs C $(p=0.021)$ and $B$ vs $C(p=0.014)$ with no significant difference in $A$ vs $B(p=0.364)$. For IL-10, there are significant increase in A vs B $(p=0.001)$ and $A$ vs $C(p<0.001)$ but not in B vs $C(p=0.157)$. Table 4 shows the median levels of TNF-alpha, IL-2, IL-4 and IL-10 in pregnant test group according to parity (primi-varida and multi-varida). It was observed that $80 \%$ of the pregnant test group was primi-varida while $20 \%$ were muti-varida. A significantly increased was observed in the median level of TNF-alpha of the multi-varida compared to primi-varida subjects of the pregnant test group $(p=0.037)$. There were no significant differences in IL-2 ( $p=0.144)$, IL-4 ( $p=0.113)$ and IL-10 ( $p=0.287)$ of both the primi-varida and multi-varida of the pregnant test group.

Table 4: Levels (median) of TNF-apha, IL-2, IL-4 and IL-10 in pregnant test group according to parity (primi varida and multi-varida).

\begin{tabular}{|c|c|c|c|c|}
\hline \multicolumn{2}{|c|}{ PRIMI N=48(80\%) } & MULTI N=12(20\%) & Mann. Whitney & p.value \\
\hline TNF- $\alpha$ & 11.6 & 16.4 & 175 & 0.037 \\
\hline IL-2 & 16.25 & 24.6 & 209 & 0.144 \\
\hline IL-4 & 0.9 & 0.65 & 202.5 & 0.113 \\
\hline IL-10 & 1.4 & 1.05 & 230.5 & 0.287 \\
\hline
\end{tabular}




\section{Discussion}

Cytokines are an extensive array of pleiotropic glycoproteins involved in the regulation of all biological processes [11]. Cytokines also act cooperatively to potentiate and modulate each other's actions in order to induce specific effects [12]. They are also capable of mutual antagonism; wherein different cytokines have opposing actions [13]. In this study, the levels of pro- and anti-inflammatory cytokines in women with threatened abortion were evaluated and results obtained. There are no significant differences observed in the anthropometric variables (age, height, body weight, body mass index and blood pressure). This shows anthropometric similarities in the different subjects used for this study. Demographic studies showed that among the pregnant women, who attend antenatal clinics, $79 \%$ are first time pregnant women (primi-varida) and $21 \%$ are not (multi-varida). Among those who have threats of miscarriage, $80 \%$ are of primi-varida and $20 \%$ are of multi-varida. Similarly, $77.5 \%$ of the apparent healthy pregnant women are of primi-varida and $21 \%$ are of multi-varida. This could be as a result of proper medical care and attention received by the primi-varida group, who are yet to experience the stages of pregnancy. Data on demographic studies also showed that of all women who were included in this study, $18.6 \%$ were of the higher class, $51.4 \%$ were of the middle class and $30 \%$ were of the lower class. Fifteen percent $(15 \%)$ of the pregnant ones with threat of miscarriage were of the higher class, $51.7 \%$ were of the middle class and $33.3 \%$ were of the lower class. Among the apparently healthy pregnant ones, $17.5 \%$ were of the higher class, $57.5 \%$ were of the middle class and $25 \%$ were of the lower class. Also $25 \%$ of the non-pregnant ones were of the higher class, $45 \%$ middle class and 30\% lower class.

There is a significant increase in the median values of the pro-inflammatory cytokines (TNF-alpha, $12.40 \mathrm{pg} / \mathrm{mL}$ and IL-2, $19.00 \mathrm{pg} /$ $\mathrm{mL}$ ) in the subjects with threats of miscarriage, when compared with the apparently healthy pregnant subjects (TNF-alpha, 1.00pg/ $\mathrm{mL}$ and IL-2, $0.85 \mathrm{pg} / \mathrm{mL}$ ) and apparently healthy non-pregnant subjects (TNF-alpha, $0.70 \mathrm{pg} / \mathrm{mL}$ and IL-2, 0.75pg/mL) $(\mathrm{p}<0.05)$. Also, only TNF-alpha was significantly increased in multi-varida compared to primi-varida of the pregnant test subjects ( $p=0.037$ ), which could be as a result of previous stimulation of the pro-inflammatory cytokines especially TNF- alpha in previous pregnancies, recurrent threats of miscarriage or imbalance in the Th1:Th2-type cytokines. This is in line with the work of Raghupathy, et al. [14,15], where they established that increased levels of pro- inflammatory cytokines is associated with pregnancy complications such as threatened and recurrent miscarriages. Similarly, there is a significant increase in the median values of the anti-inflammatory cytokines of the pregnant test subjects (IL-4, $0.85 \mathrm{pg} / \mathrm{mL}$ and IL-10, $1.35 \mathrm{pg} / \mathrm{mL}$ ), when compared with pregnant control subjects (IL-4, $0.70 \mathrm{pg} / \mathrm{mL}$ and IL-10, $0.80 \mathrm{pg} / \mathrm{mL}$ ) and non-pregnant control sub- jects $(\mathrm{IL}-4,1.10 \mathrm{pg} / \mathrm{mL}$ and IL-10, $0.70 \mathrm{pg} / \mathrm{mL})(\mathrm{p}<0.05)$. This could be as a result of a compensatory mechanism by the body to modulate the activity of the pro-inflammatory cytokines. This is in agreement with the work of Calle-Agius, et al. [16] where increased levels of TNF-alpha (pro-inflammatory cytokine) and IL-10 (anti-inflammatory) are seen in pregnant women with threats of miscarriage. In contrast, Kalinka and Radwan (2006) indicated, for the first time, that the mean concentrations of Th2-type cytokines (anti- inflammatory cytokines) and Th1-type (pro- inflammatory cytokines) did not differ significantly between women with threatened abortion and the healthy pregnant women.

Furthermore, the cytokines (TNF-alpha, IL-2, IL-4, IL-10) assessed in the pregnant control group and non-pregnant control group (B vs C) showed no significant differences (TNF-alpha; $p=0.923$, IL-2; $p=0.606$, IL-10; $p=0.157$ ) except for IL-4 with a significant decrease $(\mathrm{p}=0.014)$ in the pregnant control group when compared with the non-pregnant control group. This is as a result of the production of IL-4 in other biological activities other than pregnancy like in allergies Hershey, et al. [17].

\section{Conclusion}

From this study, it is established that the serum levels of pro-inflammatory cytokines are severely increased in pregnancy with threat of miscarriage than the anti-inflammatory cytokines. Also, TNF-alpha increases in multi-varida than in primi-varida of pregnancies with threat of miscarriage. These parameters (TNF-alpha, IL-2, IL-4 and IL-10) remain normal in apparently healthy pregnancy. Similarly, TNF-alpha, IL-2, and IL-10 are normal in non-pregnant state except for IL-4 that is involved in other biological activities. In complications such as recurrent miscarriage and threatened miscarriage, where no clear etiologies have been identified, it may be useful to ascertain the levels of some pro-inflammatory and anti-inflammatory cytokines as well as in normal pregnant condition and non-pregnant states in order to check susceptibility to complications in pregnancy especially miscarriage. It is tempting to speculate that the evaluation of "personal cytokine profiles" in women with pregnancy complications may point to an immunologic etiology. After the laboratory evaluation of the cytokines level, it could be followed by modulation of cytokine profiles by therapeutic supplementation as indicated by the "personal cytokine profile" of each patient.

Further research on the inflammatory activities of these cytokines from the initiation of pregnancy to delivery of the same set of subjects is encouraged to properly study their activities and regulations in normal pregnancies and pregnancies with pathologic conditions. Also, research on the therapeutic supplementation could shed new light on the old debate on progesterone supplementation and the most effective method of its administration. The answer 
may well lie in the individual patient; her underlying immunologic etiology, and her "personal cytokine profile." Research in this area in the coming years is bound to be intriguing and may well lead to useful therapeutic and/or preventive modalities in miscarriage that can be extended to other medical problems as well [18-21].

\section{Competing Interests}

The authors declare that they have no competing interests.

\section{Acknowledgement}

Not applicable.

\section{References}

1. Wylie L (2005) The Pregnant Uterus. Essential anatomy and physiology in maternity care ( $2^{\text {nd }}$ Edn.), Churchill Livingstone, Edinburgh, Scotland, pp. 177.

2. Abman SH, Fox WW, Polin RA (2011) Fetal and neonatal physiology, ( $4^{\text {th }}$ Edn.), Elsevier/Saunders, Philadelphia, USA, p. 46-47.

3. Sedgh G, Singh S, Hussain R (2014) Intended and unintended pregnancies worldwide in 2012 and recent trends. Studies in Family Planning 45 (3): 301-314.

4. Hurt K, Bienstock J, Fox H, Wallach E (2011) Miscarriage and Loss of pregnancy; The Johns Hopkins Manual of Gynecology and Obstetrics $\left(4^{\text {th }}\right.$ Edn.), Lippincott Williams \& Wilkins publishers, USA, pp. 438-439.

5. Garrido-Gimenez C, Alijotas-Reig, J (2015) Recurrent miscarriage: causes, evaluation and management. Postgraduate Medical Journal 91 (1073): 151-162.

6. Quenby S, Vince G, Farquharson R, Aplin J (2002) Recurrent miscarriage: A defect in nature's quality control? Human Reproduction 17: 19591963.

7. John L (2010) Cytokine. A Dictionary of Biomedicine. Oxford University Press: London. p. 85.

8. Corripio-Miyar Y, Bird S, Tsamopoulos K, Secombes CJ (2007) Cloning and expression analysis of two pro-inflammatory cytokines, IL-1 beta and IL-8, in haddock (Melanogrammus aeglefinus) Molecular Immunology. 44:1361-1373.

\section{ISSN: 2574-1241}

DOI: $10.26717 /$ BJSTR.2020.26.004394

Uzoho Cynthia T. Biomed J Sci \& Tech Res

(C) (i) This work is licensed under Creative

Submission Link: https://biomedres.us/submit-manuscript.php
9. Locksley RM, Killeen N, Lenardo MJ (2001) The TNF and TNF receptor super families: Integrating mammalian biology. Cell 104(4): 487-501.

10. Sokol CL, Barton GM, Farr AG, Medzhitov R (2008) A mechanism for the initiation of allergen-induced $\mathrm{T}$ helper type 2 responses. Nature Immunology 9(3): 310-318.

11. Kawamura K, Kawamura N, Kumagai J, Fukuda J, Tanaka T (2007) Tumor necrosis factor regulation of apoptosis in mouse preimplantation embryos and its antagonism by transforming growth factor alpha / phosphatidylionsitol 3-kinase signaling system. Biology of Reproduction 76: 611-618.

12. Weiser S, Miu J, Ball HJ, Hunt NH (2007) Interferon-gamma synergises with tumour necrosis factor and lymphotoxin-alpha to enhance the mRNA and protein expression of adhesion molecules in mouse brain endothelial cells. Cytokine 37: 84-91.

13. Numerof RP, Asadullah K (2006) Cytokine and anti-cytokine therapies for psoriasis and atopic dermatitis. BioDrugs 20: 93-103.

14. Raghupathy R, Kalinka J (2008) Cytokine imbalance in pregnancy complications and its modulation. Frontiers in Bioscience 13: 985-994.

15. Wilson R, Moor J, Jenkins C, Miller H, Walker JJ, et al. (2004) Abnormal first trimester serum IL-18 levels are associated with a poor outcome in women with a history of recurrent miscarriage. Reproductive Immunology 51(2): 156-159.

16. Calleja-Agius J, Schembri- Wismayer P, Calleja N, Brincat M, Spiteri D (2011) Obsteric outcome and cytokines levels in threatened miscarriage. Gynecology Endocrinology 27(2): 121-127.

17. Gour N, Wills-Karp M (2015) IL-4 and IL-13 signaling in allergic airway disease. Cytokine 75(1): 68-78.

18. Kalinka J, Radwan M (2006) The impact of dydrogesterone supplementation on serum cytokine profile in women with threatened abortion. American Journal of Reproduction and Immunology 55: 115121.

19. Robinson GE (2014) Pregnancy loss. Best practice \& research. Clinical obstetrics \& Gynaecology 28 (1): 169-178.

20. Scarpioni R, Ricardi M, Albertazzi V (2016) Secondary amyloidosis in autoinflammatory diseases and the role of inflammation in renal damage. World Journal of Nephrology 5(1): 66-75.

21. Zhang JM, An J (2007) Cytokines, inflammation, and pain. International Anesthesiology Clinics 45 (2): 27-37.

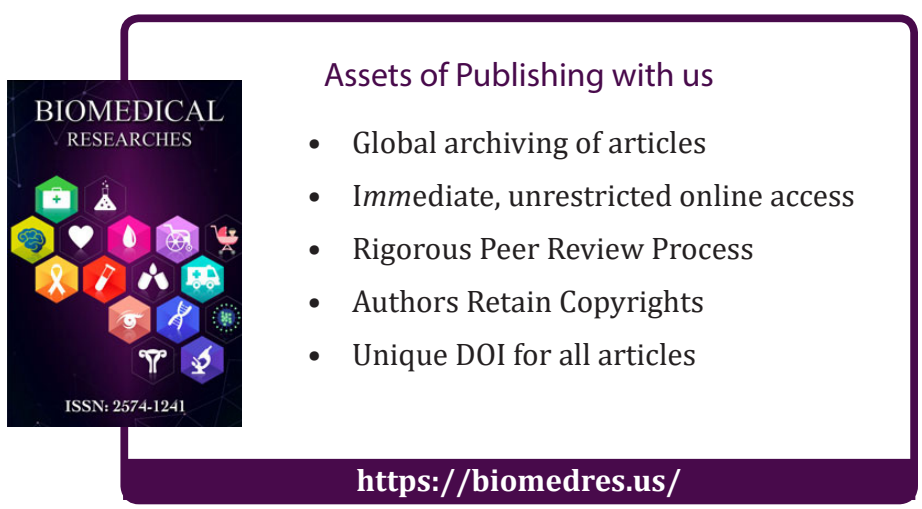

